Journal of Social and Development Sciences

Vol. 4, No. 12, pp. 526-528, Dec 2013 (ISSN 2221-1152)

\title{
Patient Perception of Health Care Services: A Comparative Study
}

\author{
*Rashmi Ananth Pai, Jayashree S. Bhat \\ Kasturba Medical College, Mangalore, Manipal, India \\ *dessairashmi@gmail.com
}

\begin{abstract}
Assessment of patient satisfaction is a measurement that obtains information or ratings from patients about their perception of the services being provided from an organization, hospital, physician, or healthcare provider and plays an increasingly important role toward accountability among health care providers. The present study aimed at comparing the patient's perception of services being provided in the government and private sectors. 120 patients (60 from each sector) natively from Karnataka, India with knowledge of English participated in this study. Subjects were asked to rate their experiences before, during and after consultation. A checklist to rate the patient satisfaction was developed. The checklist comprised of 11 questions covering the most important domains pertaining to patient satisfaction about the health care services provided. Obtained responses were statistically compared using independent $t$ test. Significant differences in the satisfaction levels of the subjects in the government and the private set ups were seen at $\mathrm{p}<$ $0.05(t=2.921,118)$. In government sector patients were better satisfied with certain aspects like the cost factor, information provided about the problem and guidance regarding intervention whereas the patients in the private sector were better satisfied with the orientation to the department, information furnished about the problem, comfort and privacy during the testing procedure.
\end{abstract}

Keywords: Patient Satisfaction, Government sector, Private sector

\section{Introduction}

Patient satisfaction assessment is a measurement that obtains reports or ratings from patients about services received from an organization, hospital, physician, or healthcare provider. Measurement of patient satisfaction plays an increasingly important role in the growing push toward accountability among health care providers (Guadagnino, 2003). Patient satisfaction measurement have traditionally been related to service improvement efforts by hospitals and health care professionals, and to fulfilling accreditation requirements of health plans, although some plans relate satisfaction scores to the cost factor. As health care professionals experience growing pressure to increase the quality of their services and outcomes, enhance the safety of their patients and lower the cost of their care, a lot of attention is being given to the accountability function of patient satisfaction scores, and to ways in which patient satisfaction measurement can be further integrated into an overall measure of clinical quality. Data on patient satisfaction is currently collected by various entities, for different purposes and at different levels in the health care system including health plans, hospitals, rating scales, physician practices etc. Only recently have efforts begun to bring uniformity to patient satisfaction measurement for hospitals. Although the redundancy and variation of patient satisfaction measurement can be minimized to permit meaningful comparisons across providers, it is important to modify the methods of patient satisfaction surveys to fulfill an expanded role of quality of care measurement.

\section{Literature Review}

During a medical interview good communication between the consultant and the patient can improve patient satisfaction (Ong et al., 1995; Weinman \& Dale, 1998) and improved patient satisfaction can lead to better health outcomes (Woolley et al., 1978; Hall et al., 1990). Many specific medical interview behaviors are thought to contribute to patient satisfaction during the medical interview, including reflection (Bertakis, Roter \& Putnam, 1991) legitimation, patient centeredness, respect, and other related factors (Coulehan \& Bloch, 1992; Cole \& Bird, 2000). There are many ways to process and analyze patient-satisfaction data. Statistical analysis can range from simple counts or frequencies of patient responses to more complex 
procedures, such as co-relational analysis or quality-control charting that will highlight relationships and variations in the data. Depending upon the ultimate goals of the program, staff availability and capability, the budget for designing and maintaining the analysis function the analysis chosen.

Buller and Buller (1987) carried out a survey assessing two general communication styles: affiliation and control. It also examined eight social characteristics of medical interviews as possible mediators of impact of physician's communication style on patient's satisfaction. In this study, affiliated styles were related positively to patient satisfaction whereas dominant/ active styles were reported to have a negative relationship with satisfaction. Severity of the illness, physician's age, physician's specialty and the number of prior visits affected the importance of the physician's communication in the patient's evaluation of care also influence the satisfaction levels to a great extent. They also reported significant differences in communication behaviors of no-claims and claims physicians in primary care physicians. But this difference is not seen among surgeons. When compared, it was found that no-claims primary care physicians used more statements of orientation, more humor and facilitation. They spent longer in routine visits than claims primary care physicians, and the length of the visit had an independent effect in predicting claims status (Levinson et al., 1997).

According to Utpal (2004), principles of good communication include: Content, process, emotional effect and follow up. He illustrated the malpractice history among primary care physicians and surgeons exploring the reason why patients sue their healthcare providers. Many malpractice suits were manifested as an expression of anger about some aspect of patient-doctor relationships and communications. Singh et al. (2009) carried out a study with an intention of developing and implementing an objective structured clinical examination evaluating the impact of a patient safety curriculum. The curriculum was implemented in a family medicine residency program with 47 trainees. Two years after commencing the curriculum, a patient safety objective structured clinical examination was developed and administered at this program and they were compared with incoming residents at the same program and to the residents at a neighboring residency program. It was found that, in a standardized patient case, error detection and error disclosure skills were better among trained residents. In a chart-based case, trained residents showed better performance in identifying deficiencies in care and described more appropriate means of addressing them.

\section{Methodology}

The study was carried out at Kasturba Medical College, Manipal University.

Subjects: 120 new patients (60 from the private hospital and 60 from a Government sector), who visited the outpatient facility for audio logical evaluation were considered for the study.

Inclusion criteria: 120 literates from a wide range of socio economic classes from both rural as well as urban areas.

Procedure: To measure patient's satisfaction, a self-administered checklist was developed. Most common indicative factors contributing to patient satisfaction were considered for the study. Subjects were asked to rate their experiences with respect to each question as 'Yes/Somewhat/No'. Resultant scores of the two groups were compared using standard chi square test.

\section{Results and Discussion}

When satisfaction level in private and government setup was compared using a chi square test, patients in the private sector yielded higher scores (mean: 30.35) as compared to those in the Government sector (mean: 29.65).This difference could be attributed to the factors like, orientation to the department, information furnished about the problem, comfort and privacy during the testing procedure. Similar factors were reported by Ong et al (1995), Weinman and Dale (1998), Coulehan and Bloch (1992), Cole and Bird (2000) which revealed that good communication between the consultant and the patient during a medical interview, patient centeredness and respect can improve patient satisfaction. In spite of the cost factor, which was higher in the private setup, the satisfaction levels were significantly higher among patients in the private sector. Significant differences in the satisfaction levels of the subjects in the government and the private set ups were seen at $\mathrm{p}<0.05(\mathrm{t}=2.921,118)$. In government sector patients were better satisfied with aspects like 
the cost factor, information provided about the problem and guidance regarding intervention whereas the patients in the private sector were better satisfied. In spite of the cost factor, satisfaction levels of patients in private sector were better as compared to those in the government sector.

\section{References}

Bertakis, K. D., Roter, D. \& Putnam, S. M. (1991). The relationship of physician medical interview style to patient satisfaction. Journal of Fam Pract, 32, 175-81.

Buller, M. K. \& Buller, D. B. (1987). Journal of health and social Behavior, 28, 375 - 388.

Cole, S. A. \& Bird, J. (2000). The medical interview: the three-function approach. St Louis: Mosby Inc.

Coulehan, J. L. \& Bloch, M. R. (1992). The medical interview: a primer for students of the art, second edition. Philadelphia: F. A. Davis Company.

Guadagnino, C. (2003). Role of patient satisfaction Press Ganey Associates

Hall, J., Feldstein, M., Fretwell, M. D., Rowe, J. W. \& Epstein, A. M. (1990). Older patients' health status and satisfaction with medical care in an HMO population. Med Care, 28, 261-70.

Levinson, W., Roter, D. L., Mullooly, J. P., Dull, V. T. \& Frankel, R. M. (1997). Physicien-patient communication. The relationship with malpractice claims among primary care physicians and surgeons. Journal of American Medical Association, 19, 277(7), 553-9.

Ong, L. M., de Haes, J. C., Hoos, A. M. \& Lammes, F. B. (1995). Doctor-patient communication: a review of the literature. Social Science Med, 40, 903-18.

Singh, R., Singh, A., Fish, R., McLean, D., Anderson, D. R. \& Singh, G. (2009). A Patient Safety Objective Structured Clinical Exam (OSCE). Journal of Patient Safety, 5(2), 55-60.

Utpal, D. (2004). Genesis and mechanics of malpractice suits - Minimizing the risks, Indian Journal of Surgery, 66(5), 301-303.

Weinman, W. S. J. \& Dale, J. (1998). Doctor-patient communication and patient satisfaction: a review. Fam Pract, 15, 480-92.

Woolley, F. R., Kane, R. L., Hughes, C. C. \& Wright, D. D. The effects of doctor-patient communication on satisfaction and outcome of care. Soc Sci Med, 12, 123-8. 